Check for updates

Cite this: RSC Adv., 2018, 8, 19524

Received 7th April 2018

Accepted 20th May 2018

DOI: $10.1039 / \mathrm{c} 8 \mathrm{ra02980f}$

rsc.li/rsc-advances

\section{Honeycomb-patterned porous films fabricated via self-organization of Tb complex-loaded amphiphilic copolymers $\dagger$}

\author{
Qian Liu, ${ }^{a}$ Chun-Na Yan, ${ }^{a}$ Yu-Chao Li, (D) ${ }^{a}$ Mei-Fang Li, ${ }^{b}$ Li-Ping Bai, ${ }^{a}$ \\ Li-Ping Wang (D) *a and Guang Li ${ }^{\star a}$
}

Amphiphilic copolymers, poly(styrene)-block-Tb complex (PS- $b$-Tb complex), were synthesized by reversible addition fragmentation chain transfer (RAFT) polymerization. The honeycomb structured porous films were fabricated via dropping the PS- $b$-Tb complex copolymer solutions on glass substrates by the breath figures method (BFM). The structure and composition of the amphiphilic copolymer PS- $b$ Tb complex were confirmed by gel permeation chromatography (GPC), Fourier transform infrared spectroscopy (FT-IR) and ${ }^{1} \mathrm{H}$ nuclear magnetic resonance spectroscopy $\left({ }^{1} \mathrm{H}\right.$ NMR). The surface morphology and elemental mapping of the highly ordered porous films were investigated by field emission scanning electron microscopy (FESEM), energy dispersive X-ray spectroscopy (EDX) and laser scanning confocal microscopy (LSCM). The results indicated that the solvent type and copolymer concentration can affect the surface morphology of the porous films. The average diameter of the pores in the porous films decreased with the polymer concentration and the molecular weight of the copolymers increased. The FESEM-EDX analysis further verified that the hydrophilic groups (Tb complex groups) were mainly distributed at the pore wall, instead of at the outer surface layer of the films, which was consistent with the LSCM results.

\section{Introduction}

The honeycomb-patterned porous films fabricated by the breath figure method (BFM) have attracted more and more attention in recent years due to their potential applications, such as in photo-electronic materials, ${ }^{1,2}$ separation membranes, ${ }^{3,4}$ biomaterials, ${ }^{5}$ drug release, ${ }^{6}$ superhydrophobic surfaces, ${ }^{7}$ and electrocatalysis. ${ }^{8} \mathrm{BFM}$ is a simple, convenient and versatile selfassembly strategy for fabrication of honeycomb-patterned porous films which was first reported by Francois and his coworkers. ${ }^{9}$ In the breath figure process, the evaporation of solvent decreases the temperature of the solution surface, thereby facilitating the condensation and growth of water droplets on the solution surface under high relative humidity. After the evaporation of water and solvent, the ordered hexagonal lattice comes into being in order to reduce the free energy. ${ }^{10,11}$ Afterward, countless important studies have been reported on porous films including the hole pattern formation

${ }^{a}$ College of Materials Science and Engineering, Liaocheng University, Liaocheng 252059, China. E-mail: wangliping5@163.com; liguang@lcu.edu.cn

${ }^{b}$ College of Life Science, Liaocheng University, Liaocheng 252059, China

$\dagger$ Electronic supplementary information (ESI) available: Supporting figures; FTIR spectra of hydrophilic PS- $b$-Tb complex copolymers; ${ }^{1} \mathrm{H}$ NMR spectrum of polystyrene (PS) and PS- $b$-Tb complex; FESEM images of porous films generated from different solvent. See DOI: 10.1039/c8ra02980f mechanism, ${ }^{12-15}$ choice, design and synthesis of polymers, ${ }^{16-21}$ effect of solvent and substrate, ${ }^{22,23}$ environment conditions, ${ }^{19,21}$ the reprocessing methods and applications ${ }^{1-8,24-26}$ and so on. Although the hole pattern formation mechanism is not completely understood at present, this method is known to require precise control over the processing environment conditions, and the polymers used in BFM usually have to be specially designed and synthesized in order to obtain a good quality in pore size and distribution..$^{27-30}$

Up to now, a variety of polymers, including star polymers, amphiphilic block copolymers, hyper-branched polymers, comb-like copolymers, and rod-coil/coil-coil block copolymers, have been employed to fabricate such porous films with different pore diameters. ${ }^{31-34}$ Various synthetic routes have been developed to synthesize the star and block polymers, particularly the living radical polymerization including reverse iodine transfer polymerization (RITP), ${ }^{35}$ atom transfer radical polymerization (ATRP), ${ }^{36}$ and reversible addition-fragmentation chain transfer (RAFT) polymerization. ${ }^{37}$ The RAFT polymerization is one of the most prominent living/controlled free radical polymerization techniques as it is applicable to a wide range of monomers to produce well-defined polymers with predictable molecular weights, composition, architecture and low polydispersity index (PDI) values.

Luminescent rare earth terbium $(\mathrm{Tb})$ complex is well-known due to their excellent luminescence characteristics, long 
luminous life time, high luminous intensity and extremely sharp emission bands (good color purity) from the electronic transitions between the 4 f energy levels, and they have been widely applied in many fields, such as photoluminescence materials, fluorescence probes and labels, electroluminescence devices and so on. ${ }^{38-40}$ In this work, we propose a simple RAFT polymerization technique to synthesize well-controlled poly(styrene)-block-Tb complex (PS- $b$-Tb complex) amphiphilic diblock copolymers for fabrication of ordered honeycomb structured porous films. The procedure for the formation of honeycomb porous films with PS- $b$-Tb complex by BFM was sketched in Fig. 1. The Tb complex is the reaction product of methacrylic acid, salicylic acid and $\mathrm{Tb}\left(\mathrm{NO}_{3}\right)_{3}$ which includes the hydrophilic monomer methacrylic acid. We use $\mathrm{Tb}$ complex as the second monomer mainly due to the following two reasons: one is that the loading of $\mathrm{Tb}$ complex into the porous films can endow the honeycomb structured porous films with fluorescent characteristic; for another, we can investigate the assemble status of hydrophilic groups in the honeycombpatterned porous films by detecting the position of rare earth $\mathrm{Tb}$ owing to the fact that the rare earth ions are directly linked to hydrophilic monomer methacrylic acid by coordinating bond. To the best of our knowledge, it is the first report to confirm the assemble status of hydrophilic groups in the porous films using rare earth $\mathrm{Tb}$ complex as a fluorescent probe. This work will provide a new way to detect the assemble status of hydrophilic groups in the porous films, promote the mechanism understandings of the breath figure process. In addition, the influence of polymer molecular weight, solvents and polymer concentration on the morphology of the films are also investigated.

\section{Experimental section}

\subsection{Materials}

Styrene (St, 99.5\%) was commercially purchased from Tianjin Kermel Chemical Reagent Co. Ltd. and distilled under reduced pressure before use. 2-Dodecylsulfanylthiocarbonylsulfanyl-2methyl-propionic acid (DMPA) was synthesized according to the previous method. ${ }^{41} \mathrm{~Tb}_{2} \mathrm{O}_{3}$, methacrylic acid (MA) and salicylic acid (SA) were purchased from Shanghai Aladdin Chemical Reagent Co. Ltd. All other chemical reagents were of analytical grade and used as received.

\subsection{Instrumental characterization}

Gel permeation chromatography (GPC1515 Waters, USA) was used to determine the molecular weights and polydispersities (PDI) with THF as the eluent at a flow rate of $0.6 \mathrm{~mL} \mathrm{~min}^{-1}$ at $30{ }^{\circ} \mathrm{C}$. Field emission scanning electron microscope (FESEM, Merlin Compact) was used to observe the surface morphology of films after being sputtered with gold using ion sputter and the energy dispersive X-ray spectroscopy (EDX) was used to map the $\mathrm{Tb}$ element at the film surface. The image of the fluorescent porous film was assessed by laser scanning confocal microscope (LSCM) (FV1200, Olympus, Japan) and measured by a $554 \mathrm{~nm}$ laser. Luminescence properties were performed on a spectrofluorometer (FLS920, Edinburgh, UK) using $323 \mathrm{~nm}$ excitation wavelength laser at room temperature. ${ }^{1} \mathrm{H}$ nuclear magnetic resonance spectroscopy $\left({ }^{1} \mathrm{H} \mathrm{NMR}\right)$ spectra were carried out on a $400 \mathrm{MHz}$ (Varian Mercury Plus 400) nuclear magnetic resonance instrument. The water contact angle was analyzed by a KRUSS DSA100 contact angle system with a drop size of $2.0 \mu \mathrm{L}$ at room temperature. The structure of the samples were characterized by Nicolet-100 Fourier transform infrared spectroscopy (FT-IR) from $400 \mathrm{~cm}^{-1}$ to $4000 \mathrm{~cm}^{-1}$ by the $\mathrm{KBr}$ tablet method.

\subsection{Synthesis of PS- $b$-Tb complex via RAFT polymerization}

Polystyrene (PS) were synthesized in cyclohexanone using DMPA as the chain transfer agent through RAFT polymerization (Scheme 1). In brief, styrene (St, $8.7 \mathrm{mmol}, 10 \mathrm{~mL}$ ), DMPA (0.17 mmol, $0.0636 \mathrm{~g})$, (2-methylpropionitrile) (AIBN) $(0.087 \mathrm{mmol}, 0.0143 \mathrm{~g})$, and cyclohexanone $(10 \mathrm{~mL})$ were mixed in a $50 \mathrm{~mL}$ round-bottomed flask with a magnetic stirrer. The reaction mixture was degassed by $\mathrm{N}_{2}$ purging and reacted at $80{ }^{\circ} \mathrm{C}$ for $12 \mathrm{~h}$. Then, the reaction mixture was diluted with tetrahydrofuran (THF), and precipitated in cold methanol. The obtained PS was dried in vacuum at $40{ }^{\circ} \mathrm{C}$. The details of the relative molecular weight and PDI of the polymers were listed in Table 1.

$\mathrm{Tb}_{2} \mathrm{O}_{3}$ (12.6 mmol, $2 \mathrm{~g}$ ) and excessive nitric acid $\left(\mathrm{HNO}_{3}\right)$ were mixed in a crucible with spirit-lamp heating and stirring. After completely volatilization of the solvent, the obtained $\mathrm{Tb}\left(\mathrm{NO}_{3}\right)_{3}$ was dried under vacuum at $30^{\circ} \mathrm{C}$. Tb complex was synthesized by mixing the $\mathrm{Tb}\left(\mathrm{NO}_{3}\right)_{3}$, MA and $\mathrm{SA}$ in a round-bottomed flask at a molar ratio of $\mathrm{Tb}\left(\mathrm{NO}_{3}\right)_{3} / \mathrm{MA} / \mathrm{SA}=1: 1: 2$. In details,

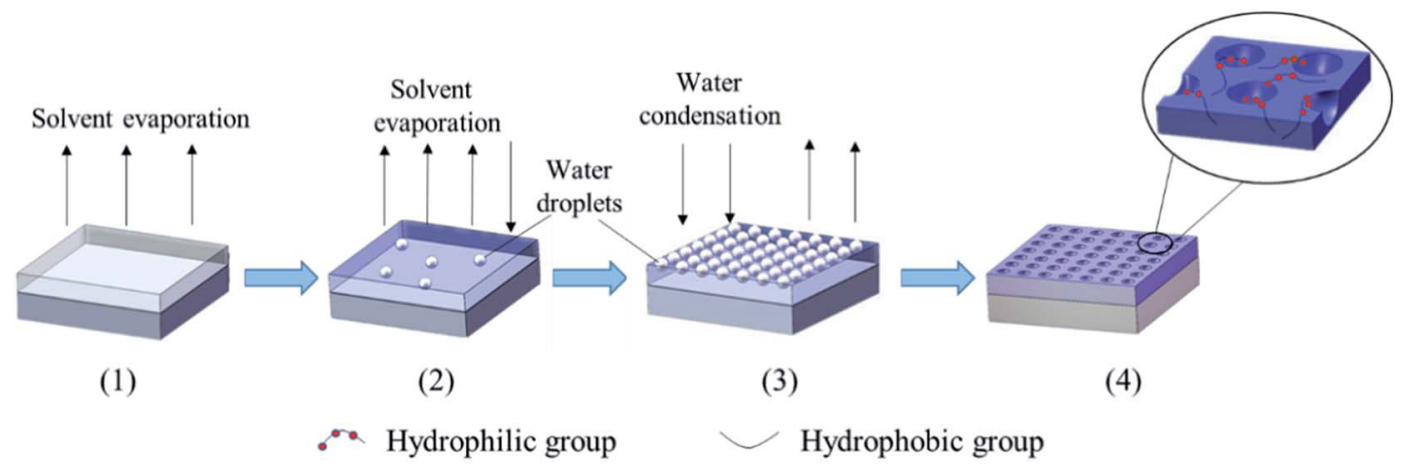

Fig. 1 Schematic illustration for the formation of honeycomb porous films with PS- $b-$ Tb complex by BFM. 


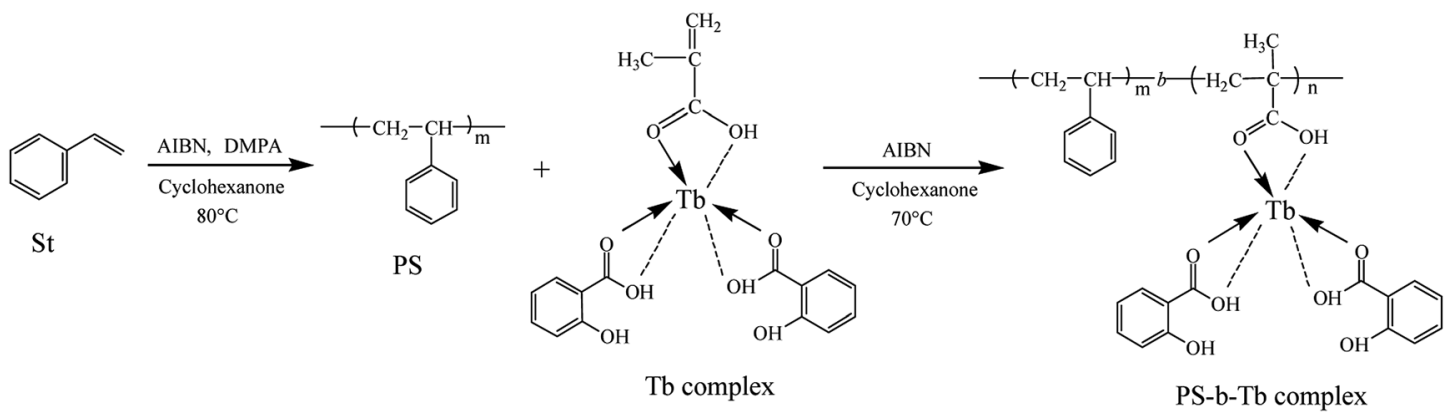

Scheme 1 The synthetic routes of polystyrene (PS) and PS- $b$-Tb complex.

$\mathrm{Tb}\left(\mathrm{NO}_{3}\right)_{3}(0.585 \mathrm{mmol}, 0.2 \mathrm{~g})$, MA (0.585 mmol, $\left.0.05 \mathrm{~mL}\right), \mathrm{SA}$ $(1.17 \mathrm{mmol}, 0.162 \mathrm{~g})$ and $1 \mathrm{~mL}$ ethanol were mixed in a $50 \mathrm{~mL}$ round-bottomed flask at room temperature for $12 \mathrm{~h}$. The $\mathrm{Tb}$ complex in ethanol was obtained. After removal of the ethanol by reduced pressure distillation, the reddish crystalline solid $\mathrm{Tb}$ complex was obtained. To verify the formation of the $\mathrm{Tb}$ complex, the $\mathrm{Tb}$ complex and $\mathrm{Tb}\left(\mathrm{NO}_{3}\right)_{3}$ were dissolved in water respectively. The $\mathrm{Tb}$ complex is insoluble in water and emits green fluorescence under UV lamp which is obviously different from $\mathrm{Tb}\left(\mathrm{NO}_{3}\right)_{3}$ (Fig. $\left.\mathrm{S} 1 \dagger\right)$. This is a characteristic of $\mathrm{Tb}$ complex. The results of the FT-IR (Fig. S2 $\dagger$ ) also proved that the terbium complex had been synthesized successfully.

The PS- $b$-Tb complex were synthesized using PS as the macroinitiator through RAFT polymerization. Briefly, PS (0.475 $\mathrm{g})$, Tb complex solution $(0.5 \mathrm{~mL})$, AIBN $(0.005 \mathrm{~g})$ and $1 \mathrm{~mL}$ cyclohexanone were added into a $50 \mathrm{~mL}$ round-bottomed flask with a magnetic stirrer. After degassing by $\mathrm{N}_{2}$ purging, the reaction mixture was heated at $70{ }^{\circ} \mathrm{C}$ for a certain time. Then the product was precipitated in cold methanol and dried under vacuum at $40{ }^{\circ} \mathrm{C}$. Schematic illustration for the synthesis of PS$b$-Tb complex was shown in Scheme 1 .

\subsection{Fabrication of the honeycomb porous thin films}

The PS- $b$-Tb complex was dissolved in various organic solvents (i.e., chloroform, dichloromethane, carbon disulfide and THF) with different concentrations $\left(2 \mathrm{mg} \mathrm{mL}^{-1}, 4 \mathrm{mg} \mathrm{mL}^{-1}, 6 \mathrm{mg}\right.$ $\mathrm{mL}^{-1}$ and $8 \mathrm{mg} \mathrm{mL}{ }^{-1}$ ). Then, an aliquot of $10 \mu \mathrm{L}$ for each polymer solution was dropped onto glass substrates $(1 \mathrm{~cm} \times 1$ $\mathrm{cm}$ ) under $1.5 \mathrm{~L} \mathrm{~min}^{-1}$ humid airflow and the relative humidity of the moist air was kept above $80 \%$. After complete evaporation

Table 1 The relative molecular weight and PDI of the polymers

\begin{tabular}{lllll}
\hline Sample & $M_{\mathrm{n}}{ }^{a}$ & $M_{\mathrm{w}}{ }^{a}$ & PDI $^{b}$ & $\begin{array}{l}\text { Reaction } \\
\text { time }\end{array}$ \\
\hline PS- $b$-Tb complex-1 & 18700 & 24500 & 1.31 & $4 \mathrm{~h}$ \\
PS- $b$-Tb complex-2 & 18900 & 24600 & 1.29 & $6 \mathrm{~h}$ \\
PS- $b$-Tb complex-3 & 19100 & 24700 & 1.29 & $8 \mathrm{~h}$ \\
PS- $b$-Tb complex-4 & 20900 & 25300 & 1.21 & $12 \mathrm{~h}$ \\
PS & 19500 & 26500 & 1.36 & $12 \mathrm{~h}$
\end{tabular}

${ }^{a}$ The molecular weights obtained by GPC with standard polystyrene as reference. ${ }^{b}$ PDI: molecular weight distribution is calculated from $M_{\mathrm{w}} / M_{\mathrm{n}}$. of solvent and water, the opaque and white thin films were obtained by the BFM at room temperature.

\section{Results and discussion}

\subsection{Structure characterization of the PS- $b$-Tb complex copolymers}

The structure of these polymers were determined by FT-IR (Fig. S2 $\dagger$ ) and ${ }^{1} \mathrm{H}$ NMR (Fig. S3-S5 $\dagger$ ). Fig. S2† shows the FT-IR spectrum of PMA, Tb complex, PS and PS- $b$-Tb complex. In the FT-IR spectra of Tb complex, the adsorption peaks at $1380 \mathrm{~cm}^{-1}$ are corresponded to $\nu_{\mathrm{s}}$ stretching vibration of $\mathrm{COO}^{-}$. The $\mathrm{C}=\mathrm{O}$ stretching vibration observed at $1658 \mathrm{~cm}^{-1}$ showed a significant red shifts compared with that of pure PMA $\left(1695 \mathrm{~cm}^{-1}\right)$, which was the result of the deprotonation of the carboxyl groups. ${ }^{42,43}$ As for the FT-IR spectra of PS, the peaks at $2800-3100 \mathrm{~cm}^{-1}$ are assigned to the $\mathrm{C}-\mathrm{H}$ stretching and the peaks at $1496 \mathrm{~cm}^{-1}$ and $1452 \mathrm{~cm}^{-1}$ are attributed to the stretching vibration absorption of $\mathrm{C}=\mathrm{C}$ bond of the benzene rings. After the block copolymerization using Tb complex as the second monomer, a new characteristic peak emerged at $1380 \mathrm{~cm}^{-1}$ corresponds to the $\mathrm{COO}^{-}$ stretching vibration of the PS- $b$-Tb complex, which indicated the successful synthesis of the PS- $b$-Tb complex. However, the peak at $1658 \mathrm{~cm}^{-1}$ of $\mathrm{C}=\mathrm{O}$ could not be clearly observed, the possible reason is the content of $\mathrm{Tb}$ complex is too low to be detected by FT-IR. Furthermore, the structure of Tb complex, PS and PS- $b$-Tb complex was further identified by ${ }^{1} \mathrm{H}$ NMR spectra analysis (Fig. S3, S4 and S5 $\dagger$ ). The ${ }^{1} \mathrm{H}$ NMR spectra of PS- $b$-Tb complex are too similar with that of PS, it is also because the content of $\mathrm{Tb}$ complex is low.

The number-average molecular weight and molecular weight distribution of PS and PS- $b$-Tb complex copolymers were determined by GPC and the results were listed in Table 1. As shown in Table 1, the number-average molecular weight and molecular weight distribution of PS determined by GPC are 19500 and 1.36, respectively. For the PS- $b$-Tb complex copolymers, with the extension of polymerization time, the numberaverage molecular weight of the block copolymers increases, which indicates the increase of the lengths of Tb complex block. The molecular weight distribution of the PS- $b$-Tb complex copolymers is relatively narrow $\left(M_{\mathrm{w}} / M_{\mathrm{n}}=1.21-1.31\right)$, which is the characteristic of a RAFT polymerization. However, the molecular weights of the PS- $b$-Tb complex copolymers with 
short polymerization time (such as $4 \mathrm{~h}, 6 \mathrm{~h}, 8 \mathrm{~h}$ ) are slightly smaller than that of the PS macro-initiator. It is probably owing to the adsorption of hydrophilic Tb complex block onto the GPC column, which leads to an addition in retention time. However, when the polymerization time increased to $12 \mathrm{~h}$, the molecular weights of the PS- $b$-Tb complex copolymers exceed that of the PS macroinitiator. This result can be explained by the fact that with the increasing of polymerization time, the hydrophilic $\mathrm{Tb}$ complex block keeps extending, the hydrodynamic volume of the PS- $b$-Tb complex copolymers increases accordingly, leading to the decrease of the retention time.

The fluorescent properties of the PS- $b$-Tb complex was obtained by monitoring the excitation spectrum of $\mathrm{Tb}^{3+}$ ion at the emission of $545 \mathrm{~nm}$. The peak at $310 \mathrm{~nm}$ was found to be the optimal excitation peak. Setting the excitation wavelength at $310 \mathrm{~nm}$, the fluorescence emission spectrum of PS- $b-\mathrm{Tb}$ complex was determined (Fig. 2). In the spectrum, four main emission peaks located at 489, 543, 584 and $621 \mathrm{~nm}$ are assigned to the electron transitions of ${ }^{5} \mathrm{D}_{4} \rightarrow{ }^{7} \mathrm{~F}_{6},{ }^{5} \mathrm{D}_{4} \rightarrow{ }^{7} \mathrm{~F}_{5}$, ${ }^{5} \mathrm{D}_{4} \rightarrow{ }^{7} \mathrm{~F}_{4}$, and ${ }^{5} \mathrm{D}_{4} \rightarrow{ }^{7} \mathrm{~F}_{3}$ of $\mathrm{Tb}^{3+}$ respectively. The results of the fluorescent properties analysis indicates that the PS- $b-\mathrm{Tb}$ complex has been synthesized successfully.

\subsection{Formation of honeycomb-patterned porous films from PS- $b$-Tb complex amphiphilic copolymers}

3.2.1 The choice and the effect of solvent type. The surface morphology of the polymer honeycomb-patterned porous films (such as pore size, order and shape of the patterns) has been found to be strongly affected by the solvent types, solution concentration, copolymers' molecular weight, the proportion of hydrophilic and hydrophobic groups. Therefore, various solvents, such as chloroform $\left(\mathrm{CHCl}_{3}\right)$, dichloromethane $\left(\mathrm{CH}_{2} \mathrm{Cl}_{2}\right)$, carbon disulfide $\left(\mathrm{CS}_{2}\right)$ and tetrahydrofuran (THF), were selected to investigate the effect on the morphology of PS$b$-Tb complex films. Fig. S6 $\uparrow$ shows the FESEM images of PS- $b$ $\mathrm{Tb}$ complex porous films generated from different solvents of (a) $\mathrm{CHCl}_{3}$, (b) $\mathrm{CH}_{2} \mathrm{Cl}_{2}$, (c) $\mathrm{CS}_{2}$ and (d) THF. It can be seen that regular porous patterns can be obtained using dichloromethane and carbon disulfide, while poor-ordered porous structures are generated by chloroform. While for the THF, the surface morphology is demonstrated as microspheres shape rather than porous films (Fig. 3d) which is named reverse breath

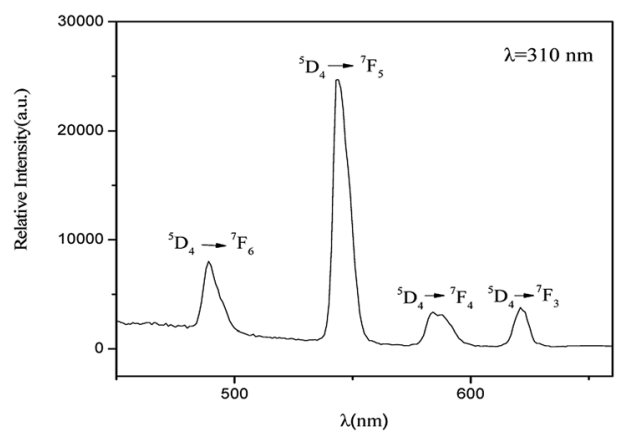

Fig. 2 The emission spectra of PS- $b-\mathrm{Tb}$ complex at excitation wavelength $\lambda=310 \mathrm{~nm}$. figures by Ferrari et $a .^{23}$ and Xiong et al. ${ }^{\mathbf{4 4}}$ They concluded that only solvents with low boiling point, high vapor pressure and low water solubility can form regular porous films. The THF has relative higher boiling point and evaporates too slowly at room temperature, leading to no condensation of water drops on the surface of the solution and resulting in reverse breath figures.

To further investigate the effect of solvent type on the fluorescent properties of PS- $b$-Tb complex solution, we took pictures of different solvents and concentrations under fluorescent light to make comparisons. As shown in Fig. 3a, the PS- $b$-Tb complex solutions of dichloromethane, chloroform and THF appear fluorescence properties, but the fluorescence properties of carbon disulfide solution disappears, which catches our attention. Accordingly, the solution was then placed at room temperature for a period of time and we found that only the $\mathrm{CS}_{2}$ solution became cloudy (Fig. 3b). Based on the above phenomena, we infer that the solubility of PS- $b$-Tb complex in $\mathrm{CS}_{2}$ is poor which leads to fluorescent quenching of PS- $b$-Tb complex solution in $\mathrm{CS}_{2}$. The photographs (UV $365 \mathrm{~nm}$ ) of PS- $b$-Tb complex solution in $\mathrm{CH}_{2} \mathrm{Cl}_{2}$ with different molecular weight and concentrations were illustrated in Fig. $3 \mathrm{c}$ and d respectively. All of them show good fluorescence characteristics. Therefore, in the following experiment, the dichloromethane was chosen as the solvent to investigate the relationships of $\mathrm{BF}$ patterns with solution concentration and copolymers' molecular weight and so on.

3.2.2 Effects of the copolymer's concentration. Fig. 4 shows the FESEM images of the porous films prepared by PS- $b$-Tb complex solutions in $\mathrm{CH}_{2} \mathrm{Cl}_{2}$ at different concentrations ((a)

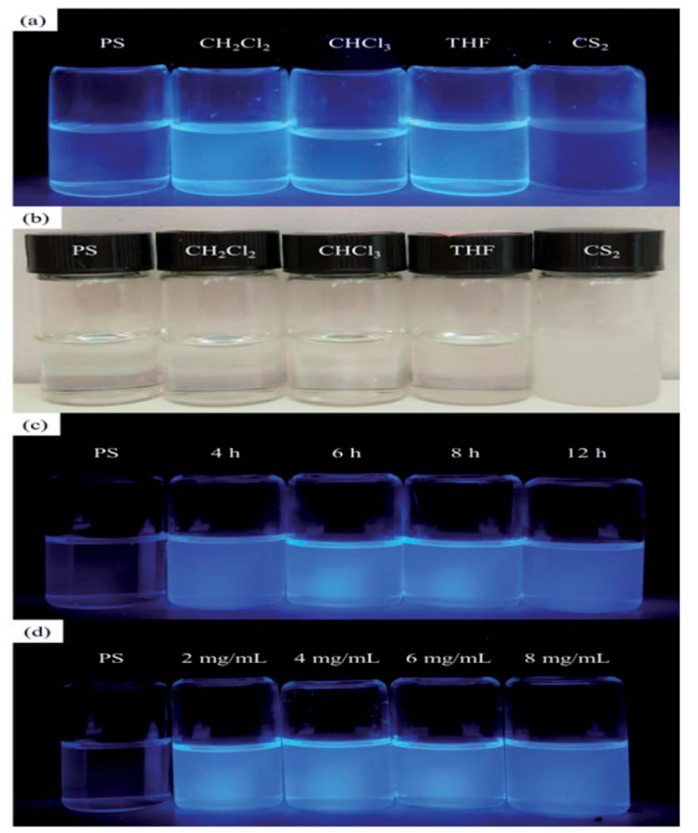

Fig. 3 Photographs (UV $365 \mathrm{~nm}$ ) of the polymers solution, (a) photographs recorded under UV $365 \mathrm{~nm}$ for PS- $b$-Tb complex-2 of $6 \mathrm{mg} \mathrm{mL} \mathrm{mL}^{-1}$ solution at different solvent and PS was dissolved in dichloromethane at $6 \mathrm{mg} \mathrm{mL}^{-1}$ solution, (b) photographs recorded under visible light of (a), (c) photographs recorded under UV $365 \mathrm{~nm}$ for PS- $b$-Tb complex of $6 \mathrm{mg} \mathrm{mL}^{-1}$ solution in $\mathrm{CH}_{2} \mathrm{Cl}_{2}$ at different reaction time, (d) photographs recorded under UV $365 \mathrm{~nm}$ for PS- $b-\mathrm{Tb}$ complex-2 in $\mathrm{CH}_{2} \mathrm{Cl}_{2}$ at different concentrations. 

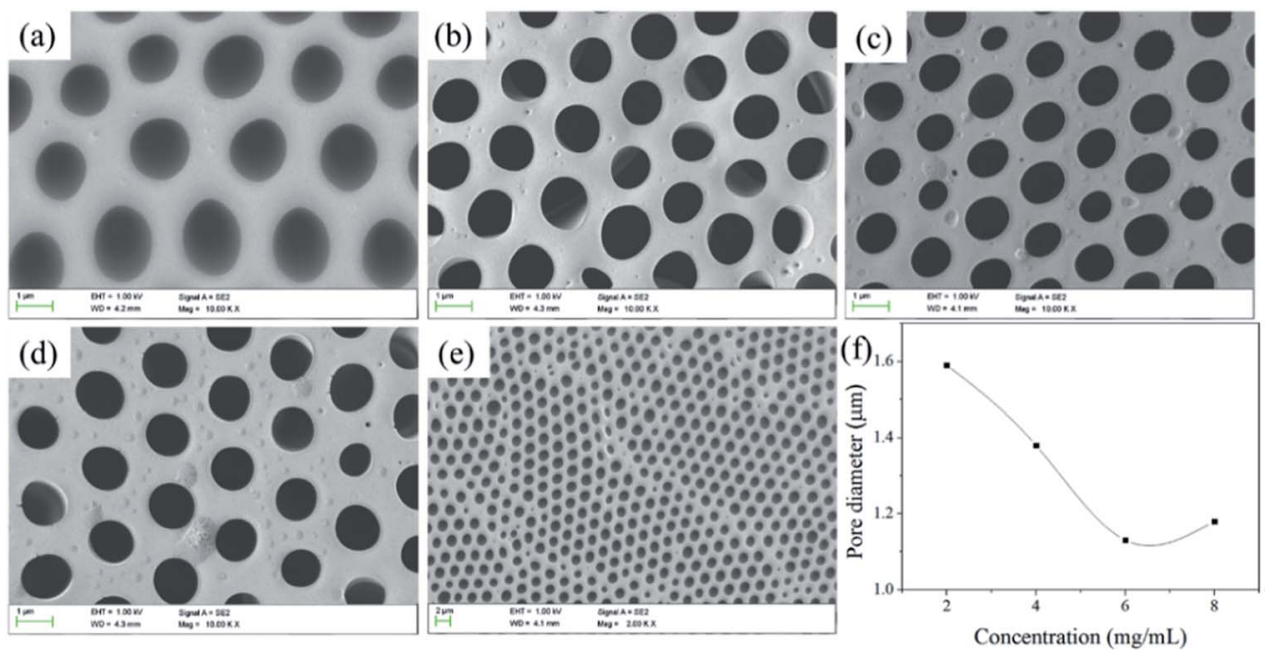

Fig. 4 FESEM images of the porous films prepared from PS- $b-\mathrm{Tb}$ complex-2 solutions in $\mathrm{CH}_{2} \mathrm{Cl}_{2}$ at different concentrations (a) $2 \mathrm{mg} \mathrm{mL}^{-1}$, $D=$ $1.59 \mu \mathrm{m}$ (b) $4 \mathrm{mg} \mathrm{mL}^{-1}, D=1.38$, (c and e) $6 \mathrm{mg} \mathrm{mL}^{-1}$ at different magnifications, $D=1.13 \mu \mathrm{m}$ and (d) $8 \mathrm{mg} \mathrm{mL}^{-1}, D=1.18 \mu \mathrm{m}$, (f) $\mathrm{correlation}$ between pore size and solution concentration.

$2 \mathrm{mg} \mathrm{mL} L^{-1}$, (b) $4 \mathrm{mg} \mathrm{mL}^{-1}$, (c) $6 \mathrm{mg} \mathrm{mL}^{-1}$ and (d) $8 \mathrm{mg} \mathrm{mL}^{-1}$ ). The pore average diameter of the porous films exhibits a tendency of decrease from $1.59 \mu \mathrm{m}$ to $1.18 \mu \mathrm{m}$ when the polymer concentration increases from $2 \mathrm{mg} \mathrm{mL}^{-1}$ to $8 \mathrm{mg}$ $\mathrm{mL}^{-1}$. When dripping the polymer solutions onto the substrate, the surface temperature of the solution cools down due to the volatilization of the solvent, thus leading to the condensation of water at the air/polymer solution interface. Once the condensed water drops touch on the surface of polymer solution, the hydrophilic end of the copolymers aggregate at the interface to prevent coalescing of water droplets. ${ }^{45}$ For the films prepared from lower concentrations, the water droplets have difficulties in immersing into polymer solution and coalescing together easily, therefore resulting in large pores and irregularly ordered porous structure. With the increase of polymer concentration, more polymers precipitate at the organic-water interface in a short time, consequently resulting in smaller pores of honeycomb structured porous films.

3.2.3 Influence of the copolymers' molecular weight and hydrophilic groups on the porous films. The molecular weight and hydrophilic groups of the copolymers also have great influence on the morphology and the pore size of the honeycomb-patterned porous films. Fig. 5 shows the FESEM images of films prepared from PS- $b$-Tb complex copolymers with different $\mathrm{Tb}$ complex block lengths (hydrophilic block). The insets are water droplet profiles and contact angles. As shown in Fig. 5, ordered porous structure is obtained with PS- $b$ Tb complex copolymers by BFM, the pore average diameter of the porous films decreases obviously from $1.55 \mu \mathrm{m}$ to $1.09 \mu \mathrm{m}$ with molecular weight of PS- $b$-Tb complex copolymers increases from 18700 to 20900 and the pore quantity raises slightly accordingly. The results confirm that the length of hydrophilic
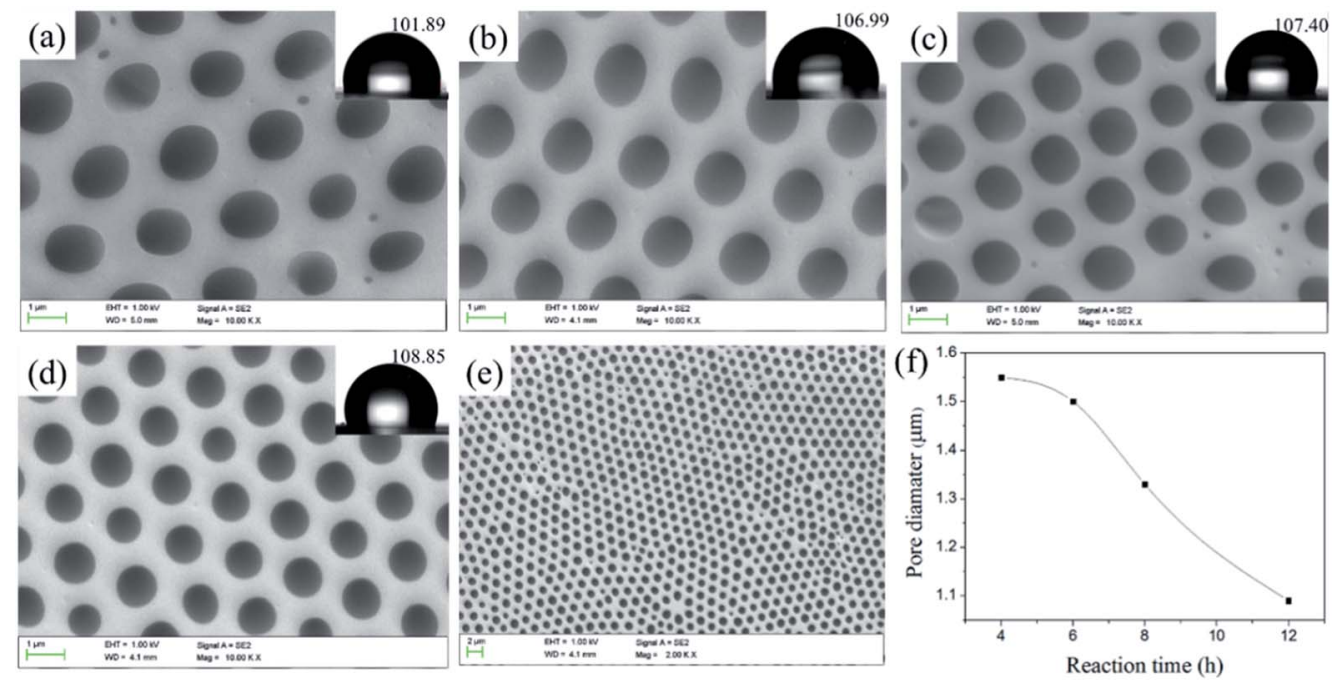

Fig. 5 FESEM images of the porous films prepared from $6 \mathrm{mg} \mathrm{mL}^{-1} \mathrm{CH}_{2} \mathrm{Cl}_{2}$ solution of PS- $b$-Tb complex, (a) PS- $b-\mathrm{Tb} c o m p l e x-1, D=1.55 \mu m$, (b) PS- $b$-Tb complex-2, $D=1.50 \mu \mathrm{m}$ (c) PS- $b$-Tb complex-3, $D=1.33 \mu \mathrm{m}$ (d and e) PS- $b$-Tb complex-4 at different magnifications, $D=1.09 \mu \mathrm{m}$, (f) correlation between pore size and reaction time. Insets show water droplet profiles and contact angles. 


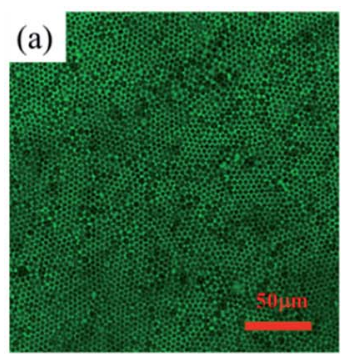

\section{(a')}

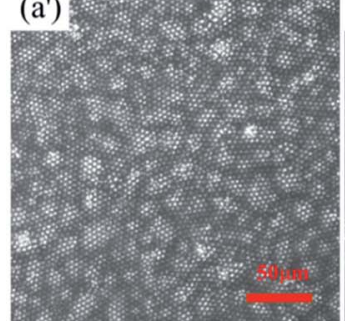

(b)

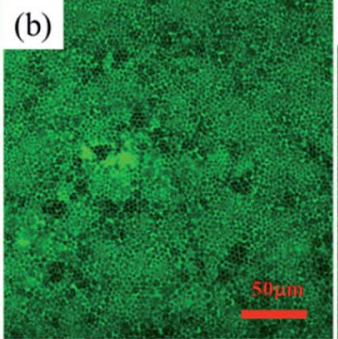

(b')

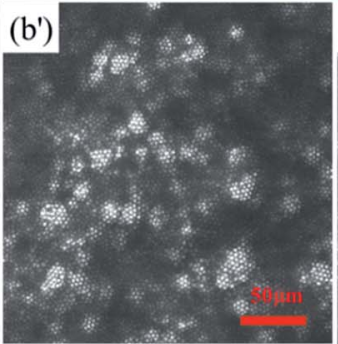

(c)
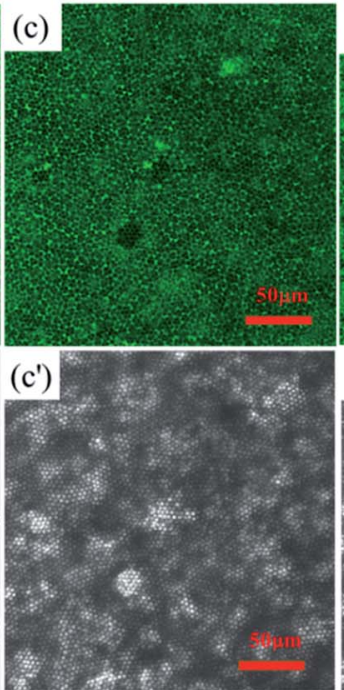

(d)
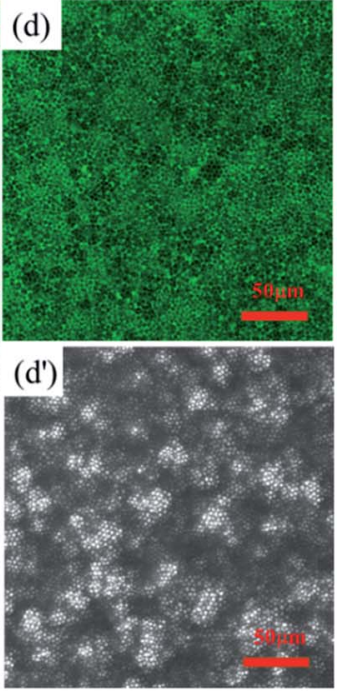

Fig. $6 \mathrm{LSCM}$ images of the porous films prepared from $6 \mathrm{mg} \mathrm{mL}{ }^{-1} \mathrm{CH}_{2} \mathrm{Cl}_{2}$ solution of PS- $b$-Tb complex: fluorescence images of (a) PS- $b$-Tb complex-1, (b) PS- $b$-Tb complex-2, (c) PS- $b$-Tb complex-3, (d) PS- $b-$ Tb complex-4; optical images of ( $a^{\prime}$ ) PS- $b-$ Tb complex-1, (b') PS- $b-$ Tb complex-2, (c') PS-b-Tb complex-3, (d') PS-b-Tb complex-4.

block is crucial for preparing porous films: the copolymer with hydrophilic block can easily stabilize the water droplets, thus resulting in regular pores. Meanwhile, in the process of the film forming, the larger the polymer molecular weight, the faster the precipitate rate of the polymer, the more difficulty the water droplets can sank into the polymer solution to decrease the pore size. $^{46,47}$ In addition, the contact angle increases with the increasing of $\mathrm{Tb}$ complex block lengths (hydrophilic block) and higher than that of the smooth PS film (considering that the external surface of the porous films is mainly enriched with PS and the water contact angle of the smooth PS film was about $89^{\circ}$ ). For the porous structure, the air is trapped underneath the droplet and effectively lowers the average surface energy, which are governed by the Cassie-Baxter theory:

$$
\cos \theta_{\mathrm{CB}}=f_{\mathrm{s}}\left(\cos \theta_{\mathrm{s}}+1\right)-1
$$

where $f_{\mathrm{s}}$ is the surface solid fraction and $\theta_{\mathrm{s}}$ is the contact angle of the smooth film. According to the Cassie-Baxter equation, the increased contact angle can be ascribed to the reduction of the surface solid fraction $\left(f_{\mathrm{s}}\right)$ of the porous films, the porous film cannot be wetted by water and form a Cassie state. ${ }^{48,49}$

3.2.4 Distribution of hydrophilic groups ( $\mathrm{Tb}$ complex groups) in the honeycomb-patterned porous films. During the $\mathrm{BF}$ process, it is believed that the hydrophilic blocks tend to aggregate themselves around the water droplets due to mutual interaction. After the evaporation of water, porous films with polar functional groups enriched inside the pores and hydrophobic blocks enriched on the external surface are achieved. In
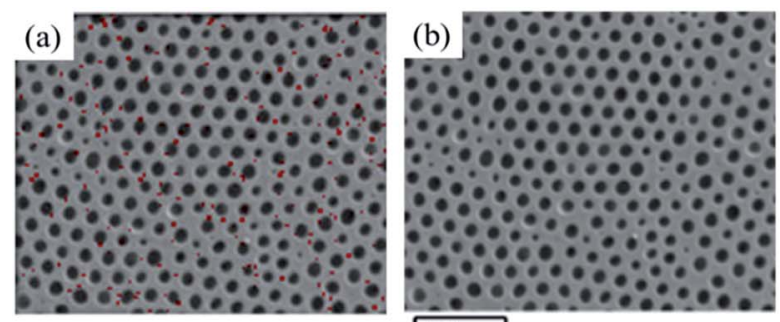

$\sqrt{10 \mu m}$

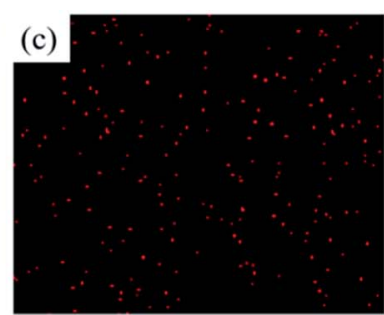

$\widehat{10 \mu m}$

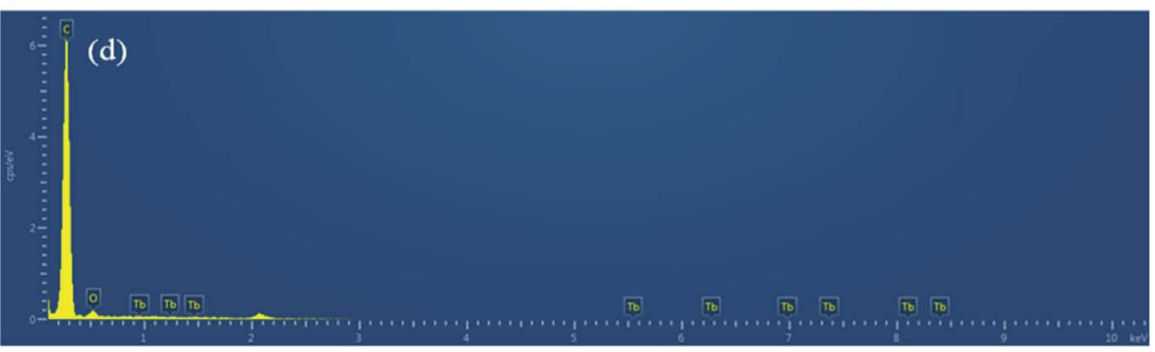

Fig. 7 FESEM images of porous films generated from $6 \mathrm{mg} \mathrm{mL}^{-1}$ solution of PS- $b$-Tb complex-2 in $\mathrm{CH}_{2} \mathrm{Cl}_{2}$, (a) EDX elemental mapping of Tb in porous films, (b) porous films of (a), (c) EDX elemental mapping of Tb in image (b), (d) EDX spectrum of (a) (the red spot in this figure represents the element $\mathrm{Tb}$ ). 
our case, an enrichment of hydrophilic block is expected. To verify the distribution of the hydrophilic blocks, Tb complex as a fluorescent probe was introduced to the block copolymers.

Rare earth element $\mathrm{Tb}$ has strong fluorescent properties. Therefore, we cast honeycomb structured PS- $b$-Tb complex porous films with $\mathrm{Tb}$ as a fluorescent probe. The Tb can mark the location of the hydrophilic section owing to the fact that the rare earth ions are directly linked to hydrophilic monomer methacrylic acid by coordinating bond. Fig. 6 shows the LSCM images of the fluorescent functional porous films investigated through a laser scanning confocal microscope. Fig. 6a-d indicates the distribution of the rare earth element $\mathrm{Tb}$ in the porous films and many fluorescent signals can be observed, Fig. $6 a^{\prime}-d^{\prime}$ displays the bright field structure of the porous films. From Fig. 6, it can be seen that the locations of fluorescent signals are mostly distributed at the pore wall. According to the formation mechanism of the porous film, ${ }^{\mathbf{1 1 , 5 0 , 5 1}}$ the hydrophilic parts can contact and wrap the water droplets and result in the formation of droplet/polymer solution interface during the process of BFM. Our experimental results further verified the mechanisms of BFM.

To further investigate the distribution of hydrophilic groups (Tb complex groups) in the honeycomb-patterned porous films, FESEM-EDX was used to detect the rare earth element Tb. Fig. 7 shows the surface elemental mapping of $\mathrm{Tb}$ images with their corresponding FESEM images for representative PS- $b$-Tb complex-2 porous films. The FESEM-EDX analysis confirms that the hydrophilic groups ( $\mathrm{Tb}$ complex groups) are mainly distributed at the pore walls, instead of at the outer surface layer of the films, which agrees well with the LSCM results.

\section{Conclusions}

The PS- $b$-Tb complex honeycomb patterned porous films were fabricated via breath figure method. The surface morphology, structure and the fluorescence properties of the porous films were characterized by FESEM, FT-IR ${ }^{1} \mathrm{H}$ NMR and LSCM, respectively. The influence of solvent types, polymer concentration and copolymers' molecular weight to the surface morphology of honeycomb patterned films were also studied. The pore average diameter of the films decreased with increasing of the molecular weight of PS- $b$-Tb complex. The porous films were endowed with fluorescent function by loading the $\mathrm{Tb}$ complex into the honeycomb patterned porous films. The hydrophilic groups (Tb complex groups) were mainly distributed at the pore walls, instead of at the outer surface layer of the porous films.

\section{Conflicts of interest}

There are no conflicts to declare.

\section{Acknowledgements}

We thank the financial supports from the Shandong province higher education science and technology program (J16LA01), the Natural Science Foundation of China (No. 51503094), Natural Science Foundation of Shandong Province
(ZR2015BQ002) and Science and Technology Innovation Fund of Liaocheng University (26312161932).

\section{References}

1 Y. He, Y. Chen, Q. Xu, J. Xu and J. Weng, ACS Appl. Mater. Interfaces, 2017, 9, 7826-7833.

2 S. Bera, M. Pal, S. Sarkar and S. Jana, ACS Appl. Mater. Interfaces, 2017, 9, 4420-4424.

3 J. Kameiab and H. Yabu, Soft Matter, 2017, 13, 7834-7839.

4 J. Zhang, Z. Meng, J. Liu, C. Schlaich, Z. Yu and X. Deng, J. Mater. Chem. A, 2017, 5, 16369-16375.

5 B. Yao, Q. Zhu, L. Yao and J. Hao, Appl. Surf. Sci., 2015, 332, 287-294.

6 Y. Su, J. Dang, H. Zhang, Y. Zhang and W. Tian, Langmuir, 2017, 33, 7393-7402.

7 Y. C. Chiu, C. C. Kuo, C. J. Lin and W. C. Chen, Soft Matter, 2011, 7, 9350-9358.

8 L. Zhang, L. Chen, S. Liu, J. Gong, Q. Tang and Z. Su, Dalton Trans., 2018, 47, 105-111.

9 G. Widawski, M. Rawiso and B. Francois, Nature, 1994, 369, 387-389.

10 M. T. Calejo, T. Ilmarinen, H. Skottman and M. Kellomäki, Acta Biomater., 2018, 66, 44-66.

11 H. Yuan, B. Yu, H. Cong, Q. Peng, Z. Yang, Y. Luo and M. Chi, J. Colloid Interface Sci., 2016, 461, 232-238.

12 C. M. Knobler and D. Beysens, Europhys. Lett., 1988, 6, 707712.

13 R. Narhe, D. Beysens and V. S. Nikolayev, Langmuir, 2004, 20, 1213-1221.

14 R. D. Narhe and D. A. Beysens, Langmuir, 2007, 23, 64866489.

15 Y. Hirai, H. Mayama, Y. Matsuo and M. Shimomura, ACS Appl. Mater. Interfaces, 2017, 9, 15814-15821.

16 M. Srinivasarao, D. Collings, A. Philips and S. Patel, Science, 2001, 292, 79-83.

17 D. Ishii and M. Shimomura, Chem. Mater., 2013, 25, 509-513.

18 D. Ishii, H. Yabu and M. Shimomura, Chem. Mater., 2009, 21, 1799-1801.

19 B. H. Wu, L. W. Wu, K. Gao, S. H. Chen, Z. K. Xu and L. S. Wan, J. Phys. Chem. C, 2018, 122, 3926-3933.

20 M. H. Stenzel-Rosenbaum, T. P. Davis, A. G. Fane and V. Chen, Angew. Chem., Int. Ed., 2001, 40, 3428-3432.

21 L. Vijaya, R. Rajan, A. Raju, T. P. D. Rajan and C. Pavithran, J. Phys. Chem. C, 2017, 121, 15154-15159.

22 T. Nishikawa, R. Ookura, J. Nishida, K. Arai, J. Hayashi, N. Kurono, T. Sawadaishi, M. Hara and M. Shimomura, Langmuir, 2002, 18, 5734-5740.

23 E. Ferrari, P. Fabbri and F. Pilati, Langmuir, 2011, 27, 18741881.

24 H. Yabu, M. Kojima, M. Tsubouchi, S. Onoue, M. Sugitani and M. Shimomura, Colloids Surf., A, 2006, 284-285, 254256.

25 O. Karthaus, Y. Hashimoto, K. Kon and Y. Tsuriga, Macromol. Rapid Commun., 2007, 28, 962-965.

26 T. Kabuto, Y. Hashimoto and O. Karthaus, Adv. Funct. Mater., 2007, 17, 3569-3573. 
27 B. Wu, M. Zhou, W. Zhang, Y. Liang, F. Li and G. Li, RSC Adv., 2017, 7, 24914-24924.

28 H. Yuan, B. Yu, H. Cong, Q. Peng, Z. Yang, Y. Luo and M. Chi, J. Colloid Interface Sci., 2016, 461, 232-238.

29 L. Vijaya, R. Rajan, A. Raju, T. P. D. Rajan and C. Pavithran, J. Phys. Chem. C, 2017, 121, 15154-15159.

30 L. Ding, A. Zhang, W. Li, H. Bai and L. Li, J. Colloid Interface Sci., 2016, 461, 179-184.

31 L. S. Wan, B. B. Ke, J. Zhang and Z. K. Xu, J. Phys. Chem. B, 2012, 116, 40-47.

32 L. P. Wang, K. Y. Yin, G. Li, Q. Liu, A. X. Deng and H. Y. Ma, React. Funct. Polym., 2016, 99, 59-64.

33 B. H. Wu, L. W. Zhu, Y. Ou, W. Tang, L. S. Wan and Z. K. Xu, J. Phys. Chem. C, 2015, 119, 1971-1979.

34 S. Zhang, T. Xu, S. Chai, L. Zhang, L. Wu and H. Li, Polymer, 2017, 117, 306-314.

35 L. P. Wang, Y. C. Li, L. F. Chen, C. L. Ban, G. Li and J. J. Ni, J. Colloid Interface Sci., 2014, 420, 112-118.

36 Y. Wang, F. Lorandi, M. Fantin, P. Chmielarz, A. A. Isse, A. Gennaro and K. Matyjaszewski, Macromolecules, 2017, 50, 8417-8425.

37 L. Shen, Q. Lu, A. Zhu, X. Lv and Z. An, ACS Macro Lett., 2017, 6, 625-631.

38 X. He, J. Lin, W. Zhai, Y. Huang, Q. Li, C. Yu, J. Liang, L. Li, Y. Fang, Z. Liu and C. Tang, J. Phys. Chem. C, 2017, 121, 19915-19921.

39 B. Ma, Y. Wu, S. Zhang, S. Wang, J. Qiu, L. Zhao, D. Guo, J. Duan, Y. Sang, L. Li, H. Jiang and H. Liu, ACS Nano, 2017, 11, 1973-1981.
40 P. Ung, M. Clerc, H. Huang, K. Qiu, H. Chao, M. Seitz, B. Boyd, B. Graham and G. Gasser, Inorg. Chem., 2017, 56, 7960-7974.

41 J. T. Lai, D. Filla and R. Shea, Macromolecules, 2002, 35, 6754-6756.

42 F. Su, C. Liu, Y. Yang, S. Ma, G. Sun and X. Yang, Mater. Res. Bull., 2017, 88, 301-307.

43 L. Liu, Q. Wang, C. Gao, H. Chen, W. Liu and Y. Tang, J. Phys. Chem. C, 2014, 118, 14511-14520.

44 X. Xiong, W. Zou, Z. Yu, J. Duan, X. Liu, S. Fan and H. Zhou, Macromolecules, 2009, 42, 9351-9356.

45 E. Bormashenko, A. Musin, Y. Bormashenko, G. Whyman, R. Pogreb and O. Gendelman, Macromol. Chem. Phys., 2007, 208, 702-709.

46 B. H. Wu, Q. Z. Zhong, Z. K. Xu and L. S. Wan, Polym. Chem., 2017, 8, 4290-4298.

47 X. Y. Li, Q. L. Zhao, T. T. Xu, J. Huang, L. H. Wei and Z. Ma, Eur. Polym. J., 2014, 50, 135-141.

48 P. C. Chen, L. S. Wan, B. B. Ke and Z. K. Xu, Langmuir, 2011, 27, 12597-12605.

49 B. B. Ke, L. S. Wan, P. C. Chen, L. Y. Zhang and Z. K. Xu, Langmuir, 2010, 26, 15982-15988.

50 J. S. Arora, T. Ponnusamy, R. Zheng, P. Venkataraman, S. R. Raghavan, D. Blakec and V. T. John, Soft Matter, 2015, 11, 5188-5191.

51 Z. Li, Q. Kong, X. Ma, D. Zang, X. Guan and X. Ren, Nanoscale, 2017, 9, 8249-8255. 